\title{
Psychiatric Presentation of Creutzfeldt-Jakob Disease: A Case Study
}

\author{
Mahmoud A. Parsa, M.D. \\ Case Western Reserve University, Cleveland, Ohio \\ Kyra Minninger \\ Case Western Reserve University, Cleveland, Ohio
}

Follow this and additional works at: https://jdc.jefferson.edu/jeffjpsychiatry

Part of the Psychiatry Commons

Let us know how access to this document benefits you

\section{Recommended Citation \\ Parsa, M.D., Mahmoud A. and Minninger, Kyra (1991) "Psychiatric Presentation of Creutzfeldt-Jakob Disease: A Case Study," Jefferson Journal of Psychiatry. Vol. 9 : Iss. 2 , Article 9. \\ DOI: https://doi.org/10.29046/JJP.009.2.016 \\ Available at: https://jdc.jefferson.edu/jeffjpsychiatry/vol9/iss2/9}

This Article is brought to you for free and open access by the Jefferson Digital Commons. The Jefferson Digital Commons is a service of Thomas Jefferson University's Center for Teaching and Learning (CTL). The Commons is a showcase for Jefferson books and journals, peer-reviewed scholarly publications, unique historical collections from the University archives, and teaching tools. The Jefferson Digital Commons allows researchers and interested readers anywhere in the world to learn about and keep up to date with Jefferson scholarship. This article has been accepted for inclusion in Jefferson Journal of Psychiatry by an authorized administrator of the Jefferson Digital Commons. For more information, please contact: JeffersonDigitalCommons@jefferson.edu. 


\title{
Psychiatric Presentation of Creutzfeldt-Jakob Disease: A Case Study
}

\author{
Mahmoud A. Parsa, M.D. \\ Kyra Minninger
}

\begin{abstract}
Creutzfeldt-Jakob disease is a fatal degenerative disorder of the central nervous system. The variability of its prodromal psychiatric and neurologic manifestation often obscures the diagnosis. This paper reports a case that illustrates the complexity of diagnosing this disease early in the clinical course, and offers a brief review of the literature.
\end{abstract}

\section{INTRODUGTION}

Creutzfeldt-Jakob disease (CJD) is a form of nervous and mental illness associated with progressive central nervous system degeneration, first described by Creutzfeldt and Jakob in the early 1920s (1,2). CJD principally affects the grey matter of cerebral cortex, brainstem, and the molecular layer of the cerebellum. Like other subacute spongiform encephalopathies in this group (Gerstmann-Straussler syndrome, kuru, scrapie, and mink encephalopathy), it is believed to be caused by histologically unconventional infectious agents called "prions" (3). Prions are treatment-resistant virus-like structures which differ from viruses because of their little, if any, nucleic acid core and their unique protein infectious component PrP27-30. The disease is found worldwide with an approximate incidence of one half case per million per year in the general population. Most cases are sporadic, but 5-15\% of cases have a genetic basis and have been clustered within families, inherited as an autosomal dominant trait with variable penetrance (4). CJD affects both sexes equally, with a mean age of onset around 60; however; patients as young as 17 and as old as 83 have been reported. Despite isolated case reports of accidental human-to-human transmission of CJD (following human growth hormone therapy, corneal transplantation, and contaminated electroencephalogram electrode implantation), researchers believe that direct inoculation of the agent remains the only proven mechanism of transmission. Forty-one percent of the cases begin as a gradually progressive mental deterioration evidenced by psychiatric disturbances; $36 \%$ initially present with nonspecific neurological symptoms only; and the remaining $23 \%$ of cases present with both mental and neurological prodromal-phase features (5). With the exception of brain biopsy, there are no specific tests for CJD. However, in the later stages of the illness, electroencephalogram (EEG) is often helpful in the diagnosis of CJD, by demonstrating repetitive, high voltage, tri- and poly-phasic sharp discharges. Because of such 
variable clinical presentations and the lack of specific diagnostic procedures, the antemortem diagnosis of CJD is difficult, and it is likely that many cases of this disease remain misdiagnosed during life.

Here we report a case of CJD with a complicated initial presentation which led to several psychiatric diagnoses over the course of one year prior to manifestation of focal neurologic deficits, dementia, and positive EEG findings characteristic of this disease.

\section{CASE REPORT}

A 44-year-old married woman, with no past psychiatric history, but a significant family history of neurotic disorders, was diagnosed with an anxiety disorder in September 1988. She had developed panic attacks in the context of significant stresses in her marriage, and was treated intermittently with amitriptyline and alprazolam, with minimal improvements.

By September 1989, the patient's symptoms had progressed and she was now experiencing light headedness, whole body numbness, and abnormal involuntary movements in the left arm, accompanied by an unsteady gait. She was noted to be forgetful and "clumsy," bumping into furniture while walking. She periodically became unresponsive, stared blankly into space, and her business affairs became increasingly chaotic. Neurological workup in a local hospital, including brain computerized tomography (CT), magnetic resonance imaging (MRI), and cerebrospinal fluid (CSF) examination, was unremarkable, except for an electroencephalogram (EEG) which showed minor nonspecific abnormalities (slowed delta and theta activity in the right fronto-temporal region). Meanwhile, the patient's condition worsened; she had multiple falls, was unable to control body movements and balance, and needed assistance in activities of daily life. She became depressed, with episodic panic attacks during which she also became very agitated and screamed, "Don't let me fall."

In November 1989, she was referred to another hospital where neurologic examination revealed bizarre choreoathetoid movements of the upper extremities, and a right gaze preference with cerebellar signs. On mental status examination she was cognitively intact but appeared to be significantly depressed (Hamilton Depressive Scale score: 39). Once again, complete laboratory workup was unremarkable except for the nonspecific minor abnormalities on EEG. The differential diagnosis included: 1) conversion disorder; 2) adjustment disorder; or 3) atypical depression. She was prescribed fluoxetine $20 \mathrm{mg}$ a day and clonazepam $0.5 \mathrm{mg}$ twice a day. The patient refused treatment and left the hospital against medical advice, but because of rapid deterioration in her condition she was readmitted to another hospital shortly thereafter. On admission, she was agitated, confused, incoherent, depressed with psychotic features (disorganized thought form, with visual/auditory hallucination), and she had developed dysphagia. She was treated briefly with a neuroleptic (haloperidol) and an antidepressant (doxepine) with no improvement. The treatment was switched to electroconvulsive therapy, and she was given two treatments following which she became mute. Electroconvulsive therapy was stopped and the patient was transferred to University Hospitals of Cleveland in late November 1989.

She was observed in a neurological unit where she was found to have marked cognitive impairment, gross apraxia, intermittent generalized myoclonic jerks and choreoathetoid movements, generalized hyper-reflexia, and unsteady gait. Head CT and MRI showed parenchymal atrophy (prominent in left frontal region); EEG was grossly abnormal and revealed generalized slowing with bilateral periodic sharp triphasic waves and epileptiform activity; 
CSF was unremarkable except for slightly decreased protein; blood count revealed leukocytosis with left shift; and blood tests were remarkable only for increased creatine kinase activity and increased erythrocyte sedimentation rate. Based on neurologic findings (especially myoclonic jerks), mental disturbances (especially memory deficits and cognitive impairments), and an abnormal EEG, a tentative diagnosis of encephalopathy secondary to CJD was made. The diagnosis was confirmed by brain biopsy which disclosed pronounced spongiform changes and mild astrocytic proliferation with spared white matter. Her hospital course was steadily downhill until her death in December 1989. Postmortem microscopic examination of patient's brain also confirmed the diagnosis of CJD. It revealed spongiform degeneration of neocortex, corpus striatum, and molecular layer of cerebellum, and an early reactive astrocytosis with minimal neuronal loss, accompanied by a recent right temporal lobe white matter microinfarct.

\section{DISCUSSION}

This case illustrates a patient with CJD, whose complexity of prodromal presentation obscured the early diagnosis. The major factors that led the physicians to consider alternative psychiatric diagnoses during the early stages of the illness were: 1) a significant history of neurotic disorders in the patient's family; 2) marital stresses which coincided with the onset of psychiatric symptoms were construed as the contributing factor to presenting symptomatology and clouded appreciation of neurological disease; and 3) the variability of neurologic symptoms and inconsistency in diagnostic tests, reinforcing the possibility of a primary psychopathology.

The literature on CJD from the early 1920s indicates that the patients described by Creutzfeldt and Jakob initially presented with psychiatric disturbances several months to years prior to the acute onset of mental and neurological deterioration. Creutzfeldt described a 22-year-old woman who apparently had a period of anorexia nervosa and "hysterical" attacks starting at age 21. As her illness progressed she became depressed, and developed personality changes, with marked manic-like episodes. Late in the course of her illness she exhibited bizarre behavior and posturing, with paranoid and nihilistic delusions, and finally developed severe cognitive impairment and dementia. All four cases described by Jakob also had a past history of anxiety, and signs and symptoms of depression for several months prior to developing marked mental and neurological dysfunction. With the progression of the illness, they demonstrated personality changes, affective disorders with psychotic features, and dementia. Verified CJD cases reported within the last 50 years also suggest the same pattern of psychiatric disturbances in a large number of the patients (6-9).

The biochemical model for psychiatric and cognitive disturbances in CJD is not yet clear. CJD principally affects the cerebral cortex, putamen, caudate nucleus, thalamus, and the molecular layer of cerebellum. Investigators have debated over the role of central neurotransmitter abnormalities in neurodegenerative disorders involving basal ganglia and cerebral cortex. Some have speculated that dopamine and gamma-aminobutyric acid (GABA) dysfunction in these areas may be responsible for motor dysfunction, cognitive impairments and dementia, as well as the psychiatric 
disturbances seen in neurodegenerative disorders such as Parkinson's disease and Huntington's disease (10-15). Several studies using positron emission tomography to assess the metabolic rates in frontal cortex and basal ganglia of patients with affective illness have suggested that depressed patients also may be relatively hypodopaminergic $(16,17)$. Like other neurodegenerative diseases involving basal ganglia and cerebral cortex, decreases in central dopaminergic and GABAergic activity may be a contributing factor to the psychiatric and neurologic dysfunction seen in CJD.

Prions have been the subject of much research and attention in recent years. Many advances have been made in defining the molecular structure of the prions, and in developing specific immunostaining techniques to detect CJD prion protein isoform in CJD-infected brain extracts $(18,19)$. However, research on human CJD is in its infancy, and because most of the diagnostic procedures are nonspecific, or reveal abnormality only in the later stages of the disease, the early diagnosis remains essentially clinical. We conclude that psychiatric symptoms are common in CJD and may at times precede the onset of neurological deficits. Therefore, we suggest that the following clinical picture should alert the physician to the possible diagnosis of CJD: a chronic history of anxiety-depressive illness with rapid progression of personality changes, cognitive impairment, and depressive-psychotic illness, associated with neurological dysfunction, evolving into a triad of dementia, myoclonus, and positive EEG findings.

\section{ACKNOWLEDGMENTS}

The authors thank Richard B. Corradi, M.D., and Herbert Y. Meltzer, M.D. from the Department of Psychiatry, and Ivan Osorio, M.D. from the Department of Neurology at the Case Western Reserve University, Cleveland, Ohio, for their helpful comments and critical review of this manuscript.

\section{REFERENCES}

1. Creutzfeldt HG: Uber eine eigenartige herdformige Erkrankug des Zentralnervensystems. Ztschr f d ges Neurol u Psychiat 57:1-18, 1920

2. Jakob A: "Uber eige der multiplen Sklerose klinisch nahestehende Erkrankung des Zentralnervensystems (spastische Pseudosklerose) mit bemerkenswertem anatomischem Befunde. Mitteilung eines vierten Falles," Med Klin 17:372-376, 1921

3. Prusiner SB: Creutzfeldt-Jakob Disease and Scrapie Prions. Alzheimer Disease and Associated Disorders 3(1/2):52-78, 1989

4. Prusiner SB, Hsiao KK, Bredesen DE, et al: Prion disease. In: Handbook of Clinical Neurology, (Eds) McKendall RR, Elsevier Science Publishers BV, 543-580, 1989

5. Brown P, Cathala F, Castaigne P, Gajdusek C: Cruetzfeldt-Jakob Disease: Clinical Analysis of a Consecutive Series of 230 Neuropathologically Verified Cases. Ann Neurol 20:597-602, 1986

6. Keshavan MS, Lishman WA, Hughes JT: Psychiatric Presentation of Creutzfeldt-Jakob Disease. Br J Psychiatry 151:260-263, 1987 
7. Davanipur Z, Alter M, Coslett HB, et al: Prolonged, Progressive, Dementia with Spongiform Encephalopathy: A Variant of Creutzfeldt-Jakob Disease? Neuroepidemiology 7:5665, 1988

8. Brown P, Cathala F, Sadowsky D, et al: Creutzfeldt-Jakob Disease in France: II. Clinical Characteristics of 124 Consecutive Verified Cases during the Decade 1968-1977. Ann Neurol 6:430-437, 1979

9. May WW: Creutzfeldt-Jakob Disease. Acta Neurol Scand 44:1-32, 1968

10. Marsden CD: Neurotransmitters and CNS Disease: Basal Ganglia Disease. Lancet: 1141-1146, 1982

11. Hagglund J, Aquilonius SM, Eckernas SA, et al: Dopamine receptor properties in Parkinson's disease and Huntington's chorea evaluated by positron emission tomography using 11C-N-methyl-spiperone. Acta Neurol Scand 75:87-94, 1987

12. Menza MA, Forman NE, Goldstein HS, et al: Parkinson's Disease, Personality, and Dopamine. J Neuropsychiatry and Clinical Neurosciences 2:241-252, 1990

13. Taylor AE, Saint-Cyr JA, Lang AE: Idiopathic Parkinson's disease: revised concepts of cognitive and affective disorders. Can J Neurol Sci 15:106-113, 1988

14. Brandt J, Folstein SE, Wong DF, et al: D2 Receptors in Huntington's Disease: Positron Emission Tomography Findings and Clinical Correlates. J Neuropsychiatry and Clinical Neurosciences 2:20-27, 1990

15. Stahl SM, Thiemann S, Faull KF, et al: Neurochemistry of Dopamine in Huntington's Dementia and Normal Aging. Arch Gen Psychiatry 43:161-164, 1986

16. Baxter Jr LR, Phelps ME, Mazziotta JC, et al: Cerebral metabolic rates for glucose in mood disorders studied with positron emission tomography (PET) and (F-18)-fluoro-2deoxyglucose (FDG). Arch Gen Psychiatry 42:441-447, 1985

17. Buchbaum MS, Wu J, DeLisi LE, Holcomb H, Kessler R, et al: Frontal Cortex and Basal Ganglia Metabolic Rates Assessed by Positron Emission Tomography with [18 F]2Deoxyglucose in Affective Illness. Journal of Affective Disorders 10:137-152, 1986

18. Serban D, Taraboulos A, DeArmond SJ, Prusiner SB: Rapid detection of Creutzfeldt-Jakob disease and scrapie prion proteins. Neurology 40:110-117, 1990

19. Piccardo P, Safar J, Ceroni M, Gajdusek DC, Gibbs Jr CJ: Immunohistochemical localization of prion protein in spongiform encephalopathies and normal brain tissue. Neurology 40:518-522, 1990 